\title{
2 Gender in the global climate governance regime
}

\author{
A day late and a dollar short?
}

\author{
Karen Morrow
}

\section{Introduction: Getting gender on the agenda}

The constitution, form, practices and culture of institutions generally (international institutions among them) are increasingly understood as important not only in mandating and structuring activities within their particular remits but also in exercising a gate-keeping role. The latter is exhibited in the voices and interests that they include/exclude from participation in their processes. Institutions and their operation ultimately embody and emphasise the broader contours of our societies and thus exhibit strongly gendered structural characteristics, which have long been the subject of feminist inquiry and analysis (Prugl and Meyer, 1999). In this context, Meryl Kenny's application of a feminist lens to path dependency (which suggests that early institutional choices shape and limit subsequent regime developments) and functionalist views of institutional change provides particularly fruitful insights for considering the shaping of international climate governance (Kenny, 2007). While often presented as alternative explanatory models, it can be said that the United Nations Framework Convention on Climate Change (UNFCCC, 1992) regime exhibits features of both approaches. In terms of path dependency, as a novel manifestation of a historically gendered international legal system, the UNFCCC regime's roots shape its institutions and institutional culture. Put briefly, it has long been argued by feminist scholars that, while ostensibly presenting itself as gender-neutral, 'international law has a gender ... that gender is a male one, and ... this skews the discipline' (Charlesworth, 2002, p. 94). Furthermore, it has been observed that it remains the case that ' $[\mathrm{t}]$ here is, by and large, a disproportionate representation of men in the institutions of international law' (ibid.). The usually uninterrogated privileged, male-dominated and largely masculinist nature of international legal institutions signally hampers their ability to evolve and to develop creative approaches to new areas, the approach on offer being to all intents and purposes 'more of the same'.

Continuing gender disparity within UN institutions raises serious questions as to the profound and seemingly intractable nature of this aspect of structural inequality, particularly in the face of much-vaunted systemic recognition and serial attempts to engage with it (Morrow, 2006). The fact that the UN has, since its inception, raised the need to address gender equality, not least as a foundational and supposedly integral part of its core human rights agenda in both the $1945 \mathrm{UN}$ 
Charter and the 1948 Universal Declaration of Human Rights, seemingly augurs well (UN OHCHR, 2014). On one level this positive impression is augmented by specific and ongoing coverage for rights-based approaches to women's participation in and across the UN and states. Rights-based coverage, for example, features strongly in the 1979 Convention on the Elimination of All Forms of Discrimination Against Women (CEDAW), Article 8 of which is germane in the current context, providing that:

States Parties shall take all appropriate measures to ensure to women, on equal terms with men and without any discrimination, the opportunity to represent their Governments at the international level and to participate in the work of international organizations.

(UN CEDAW, 1979)

Women's participation rights were further amplified by the ambitious 1995 Beijing Declaration and Platform for Action (UN OHCHR, 2014). The document features dedicated coverage for women in power and decision-making, developing institutional mechanisms for the advancement of women, and addressing women's human rights (UN BDPA, 1995, Chapter IV, sections G, H and I, respectively). The rationale for including coverage of this nature was succinctly stated:

Equality in political decision-making performs a leverage function without which it is highly unlikely that a real integration of the equality dimension in government policy-making is feasible.

(UN BDPA, 1995, para. 181)

The observation remains as cogent today as when it was made. The same holds for international policy-making contexts as they are populated by representatives selected by states. The strategic objectives for governments under the BDPA included what have become familiar themes: data collection and monitoring in the pursuit of gender balance, both domestically and in regard to UN bodies (UN BDPA, 1995, para. 190). The UN itself was also charged with putting its own house in order by pursuing gender equality in its staffing, particularly at senior level, and with collecting and disseminating data on its progress (UN BDPA, 1995, para. 193). However, while the UN's engagement with gender has matured, developing in range and sophistication over time (Morrow, 2006), it is also the case that there has been a constant need for periodic high-profile reengagement with gender issues. The latter throws a less positive light on matters, being prompted by a continuing paucity of progress on the ground. It remains the case that progress on realising rights is uneven and in consequence:

Women around the world ... regularly suffer violations of their human rights throughout their lives, and realising women's human rights has not always been a priority.

(UN OHCHR, 2014, p. 1) 
The UNFCCC is firmly located in this long-established milieu and on this ground alone would have been ripe for feminist inquiry in the cause of the imperative need to address inclusivity and equality.

At the same time, there is also a strong functionalist dimension to the institutional character of the UNFCCC system, rooted in the manner in which climate change was characterised in the fledgling regime, which has also profoundly shaped it and its approach to its role. The elements of the regime are many and their inter-relationship complex. For present purposes, the main regime actors and roles are state signatories who make up the supreme governing body of the convention in question; in the UNFCCC this is known as the Conference of Parties (CoP). Signatory states also provide the members of the regime's specialist, limited membership constituted bodies, which are charged with carrying out a range of subject-specific technical roles. The activities of the $\mathrm{CoP}$ and the constituted bodies are supported by a number of enabling bodies, notably, the regime's Secretariat, which provides general technical advice and support and organisational services and the more focused Subsidiary Body for Implementation (SBI). Additionally, a number of recognised non-state actors now play a variety of roles in regime activities. In initially characterising climate change as a technical issue, suitable for traditional state-centric international law coverage and dominated by the search for scientific and economic 'fixes' (themselves reliant on male-dominated disciplines) its pervasive, cross-cutting complex nature was not fully addressed (UN FCCC, 1992; Morrow, 2017a, p. 31). The social dimensions of climate change were initially largely absent from consideration in the regime, though, in fairness to the UNFCCC Secretariat, it recognised this lack at a fairly early stage and expanded its stakeholder engagement beyond states to embrace (some) major societal groups in its activities. However, the approach adopted tended to augment the initial masculinist dominance of technical and economic concerns within the regime (Morrow, 2017b, p. 39). The various voids that this approach propagated and perpetuated now seem obvious, yet took many years for the UNFCCC regime to grasp, in part because:

Essentially, people tend to assume that our own way of thinking about or doing things is typical. ... If the majority of people in power are men - and they are - the majority of people in power just don't see it. Male bias just looks like 'common sense' to them.

(Perez, 2019, p. 270)

Tellingly, the newly expansive approach towards stakeholder groups did not, for many years and despite vigorous and sustained campaigning, extend to women. The regime's failure to act decisively on gender inclusion was mystifying on a number of levels, not least as the UNFCCC had long been on the record as recognising the fact that women were underrepresented in its activities and on its constituted bodies and that this needed to be addressed (UN FCCC, 2001). This apperception did not, however, prompt an effective response, with calls for data collection and dissemination with reference to the gender composition of 
the regime's constituted bodies failing to generate much impact. Alongside this, it took the best part of two decades for the constituency status enjoyed by other major groups under the regime to finally be accorded to the Women and Gender Constituency (WGC) in 2011 (Morrow, 2017a, pp. 33, 37-38). This development coincided with a higher profile for gender in the context of discussions about climate change among UN institutions more generally, notably in bodies with remits in gender and in environmental matters (Morrow, 2017a, pp. 34-35). It was more particularly prompted by activity in the cognate 'Rio Conventions', comprising the UNFCCC itself, the Convention on Biodiversity (CBD) and the subsequently adopted United Nations Framework Convention to Combat Desertification (UNCCD) in which gender featured prominently, in their preparations for the Rio+20 Conference in 2012. The activities of the CBD and the UNCCD had seen gender not only raised but also engaged with (albeit to varying degrees) at a regime level in a way that, until this point, those of the UNFCCC had not and the latter was, in comparison a laggard (CBD, UNCCD, UNFCCC, 2012, p. 5; Morrow, 2017a, p. 35).

\section{Gender landmarks in the UNFCCC regime}

\section{Monitoring and reporting on gender representation}

Decision 23/CP.18, adopted at the UNFCCC CoP in Doha in 2012, arguably signals the start of an attempt to promote serious engagement with gender in global climate change governance (UN FCCC, 2012). The Decision's title set out its stall very clearly: 'Promoting gender balance and improving the participation of Women in UNFCCC negotiations and in the representation of Parties in bodies established pursuant to the Convention or the Kyoto Protocol'. Decision 23/CP.18 was hugely important in both principle and evolving regime practice. It not only served to reiterate concerns previously (though sporadically) raised about the gender composition of the UNFCCC's constituted bodies; it also looked explicitly to the gender make-up of signatory state delegations. More importantly still, it set the scene for gender to become a regular (rather than merely occasional) regime agenda item. The crucial element of Decision 23/ CP.18 lay in beginning to construct a factual foundation upon which to ground regime actions on gender, by regularising and enhancing monitoring, and reporting on gender representation in state delegations and constituted bodies. In consequence, annual reports on the composition have featured in the UNFCCC's regular diet of business since 2013 and this remains a central component of how the regime presents its coverage of gender issues. While a more granular analysis is not possible within the confines of the current chapter, even a basic exploration of material drawn from the regime's annual gender composition reports from 2013 to date is revealing (UN FCCC Gender and Climate Change Documents, n.d.). Figure 2.1 takes the average representation of women in the UNFCCC's constituted bodies ${ }^{1}$ as an example and shows that taken overall, despite the UNFCCC's regime machinery shifting to and gradually ratcheting up the active 
Average Percentage Female and Male Membership of UNFCCC

Constituted Bodies Drawn from Gender Composition Reports



Figure 2.1 Average percentage female and male membership of UNFCCC constituted bodies drawn from gender composition reports

UNFCCC Highest and Lowest Percentages of Female

Representation on Constituted Bodies 2013-2019

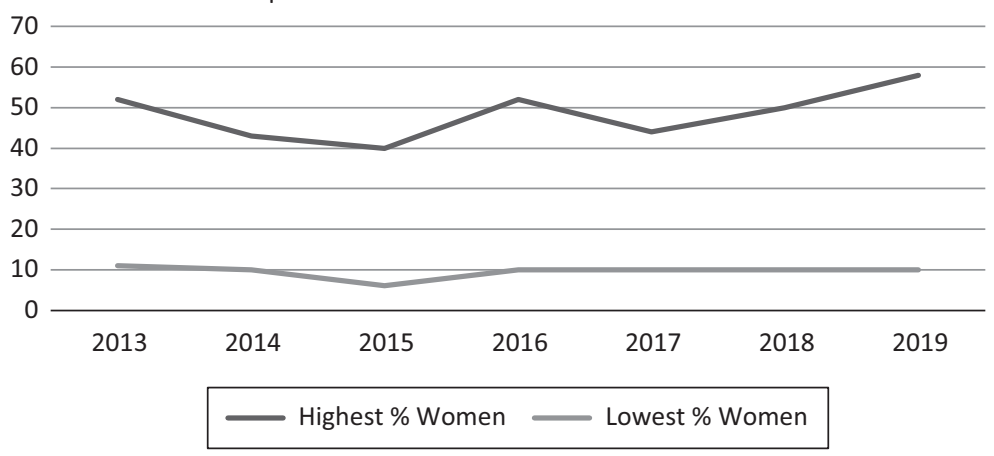

Figure 2.2 UNFCCC highest and lowest percentages of female representation on constituted bodies 2013-2019

promotion of gender equality, progress has been scant. This remains the case when the expansion over this period of the number of constituted bodies from 11 to 15 is accounted for.

Figure 2.2, showing the top and bottom of the range of percentages of women sitting on constituted bodies, is also disappointing. While, as Figure 2.2 shows, particularly from 2017 onwards, upper averages are improving, the lower register remains stubbornly on or below 10\%. Figure 2.3 likewise shows a bifurcated picture: while in 2019 female representation was 30\% and above on nine of the regime's 15 constituted bodies, closer inspection of the source material reveals that there is still a long way to go. Of these nine bodies, women's representation in eight sits between 30-39\%, and of these, only three register above 35\%. 


\section{Karen Morrow}

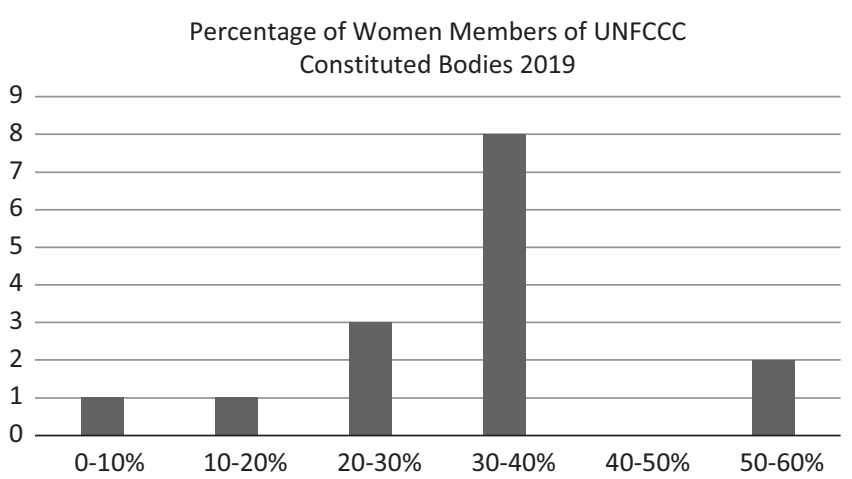

Figure 2.3 Percentage of women members of UNFCCC constituted bodies 2019

Only the Adaptation Committee (which has consistently been among the better performers on women's representation, and more so since 2016) and the Paris Committee on Capacity Building exceed this, though both include well over $50 \%$ female members. Furthermore, in 2019, five constituted bodies still have a less than $30 \%$ female complement. At the bottom of the lower range of representation, the powerful Executive Board of the Clean Development Mechanism, which, while now an outlier rather than, as previously, typical of many of its peer bodies, persists at a damning 10\% (where it has stood since 2015, falling from $20 \%$ in 2014).

\section{Acting to change institutional culture}

The provision of statistical data remains the most prominent strand in the UNFCCC regime's own account of its engagement with gender. However, while such material is necessary to provide the basis for debate seeking to alter institutional culture and serves to capture what Lena Wängnerud (2009) has termed descriptive representation, it cannot suffice to promote effective engagement with gender issues. This requires a deeper, conscious and active engagement with equality, which, as revealed by work on domestic parliaments and gender, inevitably collides directly with gendered systems, structures and practices (Wängnerud, 2009, p. 52; Criado Perez, 2019, pp. 271-286). The figures above strongly suggest that the same is true for the regime machinery of international agreements such as the UNFCCC, where data production and dissemination have not prompted appreciable progress. While the UNFCCC constituted bodies have a shorter history than domestic institutions, they are, as discussed above, grafted on to a system hallmarked by entrenched gender inequality. In any event, even presence in numbers, while necessary to progress gender equality in a system, is not necessarily sufficient (Wängnerud, 2009, p. 59).

Thus, in addition to considering women's presence in regime bodies, it is also crucial to examine what Wängnerud (2009) terms substantive representation, 
that is, the effects of women's presence on the regime. In the context of the UNFCCC, these will be examined by considering indicative developments in the regime's gender culture through the changing nature of the coverage it offers to gender issues.

The UNFCCC has not confined its activities to recording the numbers of women present in its constituent bodies and national delegations. The search for increased efficacy saw the gender agenda coalesce in the activities of the Conference of Parties itself, with the adoption of a suite of important decisions shaping the regime's new approach. These documents are significant in that, while they continue to be led by quantitative elements, focusing on participation metrics, this is now coupled with commitments to substantive action with more qualitative dimensions. The latter demonstrates a shift, seeking to improve not just the numbers of women active in regime processes but also their ability to participate meaningfully in them. Decision 18/CP20 on the Lima Work Programme on Gender (LWPG) was a landmark in this process (UN FCCC, 2014). The document, weighing in at only two pages, was brief but foundational, focusing on improving the coherence of the regime's work to address gender through mainstreaming in the UNFCCC regime. Significantly, the contextual markers identified by the LWPG included CEDAW and the UN BDPA. The work programme was set up to pursue gender balance and develop gender-responsive climate policy (the meaning of which it promises to clarify) to improve women's participation in the regime's constituted bodies. The programme included strengthened reporting requirements, but also looked to substantive matters centred on training and capacity building and, perhaps most importantly of all, committed to a review in 2016, keeping progress under scrutiny (UN FCCC, 2014, paras. 3-6 and 16, respectively).

Incremental progress continued with the adoption of Decision 3/CP.23 (UNFCCC, 2017), which added a gender action plan (GAP) to the LWPG. The CoP had requested that the SBI develop the GAP in Decision 21/CP.22, with a view to supporting the implementation of gender-related decisions and mandates within the UNFCCC. A fairly broad range of potential courses of action was outlined therein, including 'identifying priority areas, key activities and indicators, timelines for implementation ... responsible and key actors and indicative resource requirements for each activity' and enhanced monitoring and review processes (UN FCCC, 2016, para. 27). If the LWPG provided the skeleton of the regime's new, ostensibly more coherent approach to gender, the GAP put flesh on these bones. The GAP ran until 2019 and identified five priority areas, deliverables for each and the actors responsible for them. The five priority areas comprised knowledge-sharing, gender balance, coherence, implementation and monitoring and reporting. While some of these areas share a strong quantitative bent with earlier initiatives, the package taken as a whole now demonstrates a mixed approach, though with qualitative elements continuing to play a part across the board. The hybrid approach espoused is apparent, for example, in priority area $\mathrm{B}$, on gender balance - which on the face of it would seem to be largely quantitative. However, while the deliverables identified for it included quantitative 


\section{Karen Morrow}

elements, such as the promotion of travel funds for female participants in regime process, and information about gender balance to accompany recruitment to constituted bodies, it also featured two activities centred on training, which also looked to qualitative considerations concerning capacity-building. The responsible actors identified included state parties, the UNFCCC Secretariat, other UN bodies and relevant external organisations (UNFCCC, 2017, Annex). The GAP is presented as a four-page annex to Decision 3/CP.23, the first of which outlined the five priority areas and the remaining three of which comprised closely written tables for each of them, detailing activities, the attribution of responsibilities, timelines, deliverables/outputs and the level at which implementation is required (local, national, regional and/or international). The task and action approach adopted in the GAP has a number of advantages in terms of expectation management and transparency for all actors within the UNFCCC system. While a rational and coherent approach does not of itself guarantee progress, it does at least serve to offer desirable consistency.

Pursuant to the LWPG and the GAP's stated priority to ensure that gender was integrated into the work of 11 of the UNFCCC's constituted bodies, ${ }^{2}$ in 2019 the UNFCCC Secretariat produced a desk-based synthesis report on progress (or the lack of it) to date on reporting of gender coverage within the various mandates involved (UN FCCC, 2019a). The report identified basic progress through time, in that while in 2017 only six constituted bodies mentioned gender as part of their regular reporting processes, in 2018 this had increased to 11 . However, most were acknowledged as offering at best cursory coverage, indicating only marginal improvement. Of the seven that reported in some depth on their progress in integrating gender into their processes and work, only three reported that they had instituted practical action such as setting up working groups and/or gender focal points or instituting their own gender action plans (UN FCCCC, 2019a, para. 8-10). Slight improvement on previous practice must, however, be set against the fact that, the UNFCCC's multiple efforts in the last few years notwithstanding, coverage was at best uneven. It ranged from comprehensive approaches by some through to two constituted bodies that provided such limited information that it was not possible to determine their progress. Furthermore, where gender was reported upon, the approach adopted was idiosyncratic, making comparison and the sharing of best practice challenging. The provision of UNFCCC guidance on the form and substance required for gender progress reports was suggested to improve the utility of the reporting process (UN FCCC, 2019a, para. 121).

The LWPG and GAP themselves fell to be reviewed by the SBI (UN FCCC, $2019 \mathrm{~b}$ ). The SBl's evaluation of progress on the five priorities, based on submissions from a range of state parties and observer organisations, also pointed to the importance of the LWPG to the regime's institutional culture as a framework for gender action and the GAP as the practical focus for action. In the latter context, the LMPG and GAP were identified as providing a platform for stakeholders to exchange information on and to advance the five priorities. Review participants also took the opportunity to suggest improvements, showing that the LWPG and GAP are not only important in themselves but also part of an ongoing and iterative 
process. This is confirmed by the adoption of Decision 3/CP.25 of the Enhanced Lima Work Programme on Gender (ELWPG) and its gender action plan (UN FCCC, 2019c), which are to run until 2024. The ELWPG rehearses the usual background mantra of the climate change regime: reiterating links with other $\mathrm{UN}$ remits (notably the SDGs), exhorting states to act and requesting that the Secretariat continue to provide support to enable them to do so. However, as anyone familiar with the UNFCCC's attempts to improve its practice on gender equality fully expects, it also clearly acknowledges that, previous efforts notwithstanding, there is a

persistent lack of progress in and the urgent need for improving the representation of women in Party delegations and constituted bodies.

(UN FCCC, 2019c, para. 2)

The augmented GAP is similar in length, content and organisation to its predecessor - and in many ways also indicates a 'more of the same' approach. Once again taking priority area B, gender balance, participation and women's leadership, as an example, travel funding and training remain as identified activities. An additional strand of activity concerns working with the Local Communities and Indigenous Peoples Platform Facilitative Working Group (LCIPPFWG) 'on women's leadership and enhancing the participation of local communities and indigenous women in climate policy and action ... to the extent that it is consistent with the workplan of the ... [LCIPPFWG] ... and within existing resources' (UN FCCC, 2019c, B3). Given that women's participation is often contentious in these contexts (UN Secretariat of the Permanent Forum on Indigenous Issues [SPFII] et al., 2010), it is difficult to gauge how effective this activity will be, beyond initiating a dialogue on the issues. However, in a crucial exception to the prevalent 'more of the same' approach, the most significant development in the new GAP involves priority area $\mathrm{D}$, gender-responsive implementation and means of implementation. This sees a shift in emphasis in the action plan, with seven activity areas identified, a significant increase on the three covered in the 2017 version. Priorities continue developing work with various women's organisations to better inform approaches to gender issues but extend to: improving the provision of gender-disaggregated data, sharing good practice on mainstreaming gender in climate policy, and support for integrating gender into the central funding and technical concerns of the regime. The fact that the implementation strand is now providing for the main thrust of activity in the GAP is significant in drawing attention to gender implications in some of the core practical elements of the UNFCCC.

In addition to the work programmes and action plans, the UNFCCC charged its Secretariat with securing practical improvements in the regime's operation and outputs by developing a series of technical papers to inform the regime's approach to gender. Such synchronous developments were geared to promote deeper integration of gender into the regime's architecture. One important example lay in identifying possible actions in the workstreams of the regime's constituted bodies that were, or could be, integrated to deliver informed reporting on 
progress towards the parties' goals on gender balance and gender-responsive climate policy (UN FCCC TP, 2018). The technical papers, in turn, form the basis for further work - in this example, the CoP in Decision 3/CP.23 (UNFCCC, 2017) requested that its outcomes and recommendations form the basis of a dialogue between the chairs of the constituted bodies, to share experience and expertise and build capacity for effective engagement with gender.

\section{Increasing the profile and visibility of gender in the UNFCCC regime}

If progress on gender representation and integration leaves much to be desired, it is nevertheless the case that gender has become an established (if unevenly realised) agenda item across UNFCCC processes. Gender coverage is now also a much more visible and accessible presence on the organisation's website. In addition to prominent positioning as one of the regime's headline topics, collated coverage of relevant regime decisions and documents pertaining to gender is now provided (UN FCCC Gender and Climate Change Documents, n.d.). The gender topic is also furnished with cross-cutting links to other core areas of the UNFCCC regime, namely adaptation, mitigation, capacity-building, technology, climate finance and cross-cutting topics (UN FCCC Topics, n.d.).

As illustrated in Figure 2.4, the coverage of gender in regime documents has broadly (if initially sporadically) increased over time, admittedly from paltry beginnings in 2001. More consistent development, prompted by shifts in the priority that the UNFCCC has accorded to gender in its institutional activities (discussed above), began in 2012 and relevant regime activity since has been considerably more frequent and, while not constant, operates at a level that demonstrates at least a core level of engagement each year.

Other forms of more public-facing engagement by the UNFCCC regime also flourished on the UNFCCC's belated awakening to gender issues. One prominent

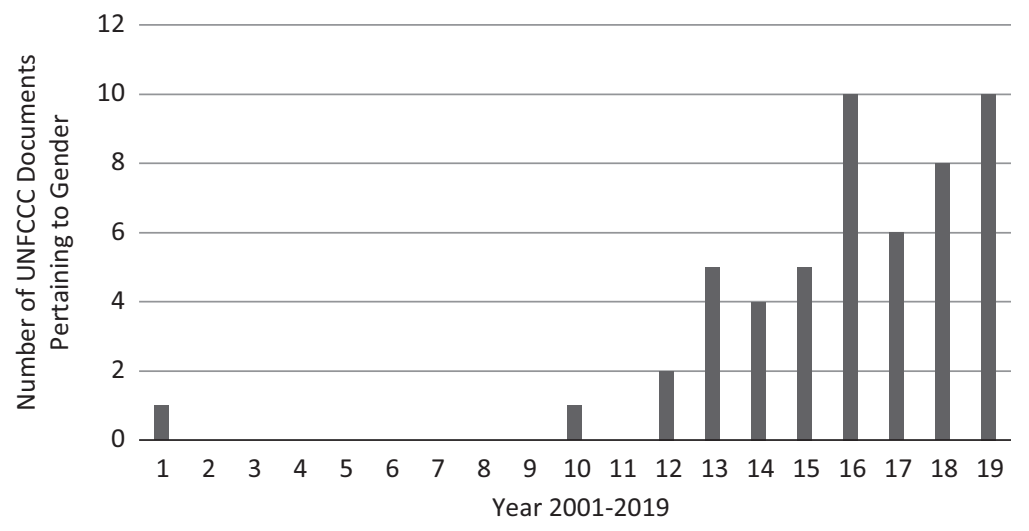

Figure 2.4 Numbers of UNFCCC documents pertaining per gender 
development was the addition of a regular 'Gender Day' event to the meetings of the conference of parties from 2012 onwards (UN Women, 2012). A second innovation saw the regular inclusion of practically oriented gender-based workshops at regime meetings (UN FCCC, 2013). While these developments could have been fairly superficial, they have not only generated headlines but have also raised the profile of gender issues in the main business processes of the UNFCCC, at the same time as providing opportunities to interrogate the regime's shortcomings and attempt to build capacity to address them. Gender days have, for example, highlighted progress on gender equality and climate change (2014), the economic case for gender-responsive climate action (2017) and gender and national adaptation plans (2019). Gender workshops (reports on which are subsequently fed into the regime by its Secretariat) have addressed core topics such as gender and mitigation (2015), gender and adaptation (2016) and the gender-differentiated impacts of climate change and gender-responsive climate policy and action (2018). It is an indication of continuing institutional commitment that workshops on integrating gender into national climate actions have not been side-lined by the COVID-19 pandemic but instead moved online in a development which should help to retain their momentum (UN FCCC, 2020).

\section{The Paris Agreement and gender}

Much is made by the UNFCCC on its website of the fact that gender attained preambular status in the Paris Agreement (PA), which acknowledges that, as

climate change is a common concern of humankind, Parties should, when taking action to address climate change, respect, promote and consider their respective obligations on human rights, the right to health, the rights of indigenous peoples, local communities, migrants, children, persons with disabilities and people in vulnerable situations and the right to development, as well as gender equality, empowerment of women and intergenerational equity.

(UN FCCC, 2015b, emphasis added)

However, while the PA could have been a springboard for a more balanced, socially directed approach to climate change coming to the fore, in many ways it missed the mark, not least with regard to gender, which garnered a scant three mentions in the Agreement's main text. While the preamble to the PA adopts a more socially contextualised approach to climate change than hitherto, its role in the regime is comparatively limited, largely serving to provide an interpretative context for the substantive articles included in the main body of the Agreement. Gender had been a live issue during the negotiating process and prominent in the draft agreement - it was mentioned nine times in the bracketed negotiating text (UN FCCC, 2015a). Many were, however, hugely disappointed by what the PA actually delivered on gender, as the inter-state negotiating process took effect. One result was that elements perceived by some states as controversial, including, as Rochette observes, most of those on gender, were excised from the 
text (Rochette, 2017, p. 254). In the Agreement as adopted, gender was siloed in coverage of adaptation (UN FCCC, 2015b, Article 7) and mitigation (UN FCCC, 2015b, Article 11).

The use of language in the preamble to the PA, calling on states to 'respect, promote and consider' their human rights obligations, is remarkable and arguably signals a great deal in attitudinal terms. The usual parlance with regard to states' human rights obligations requires them to 'respect, protect and fulfil' (emphasis added) them. In short, under the guise of 'respect', states are expected to refrain from interfering with human rights. To 'protect' requires that states address human rights issues for individuals and groups - 'promotion' is a much looser, hortatory term and not a like-for-like substitute. The obligation to 'fulfil' requires states to take positive action to deliver on the human rights that they have committed to (UN OHCHR, n.d.). An obligation merely to 'consider' (i.e. to take into account) is not commensurate with an obligation to fulfil (i.e. deliver) on human rights. The orientation of this preambular clause of the PA is significant in real terms, as it is now seen as representing part of the institutionally accepted context for actions under the UNFCCC (UN FCCC, 2019c). This careful and deliberate use of language is crucially important - in effect, it seeks to pay lipservice to human rights, while at the same time diluting state obligations to act to secure those rights that are increasingly recognised by the UN's human rights machinery to be infringed/infringeable by climate change (UN OHCHR, 2019). This is particularly significant with regard to gender, as women are recognised as a particularly vulnerable group in the context of climate change and as having protected human rights in this regard (UN OHCHR, 2019, paras. 45-47 and 64, respectively). Such gendered effects of climate change have long been recognised by many UN entities (Morrow, 2017a, p. 34), not least CEDAW (most recently in CEDAW, 2018).

\section{The Sustainable Development Goals, Agenda 2030 and gender}

The inclusion of reference to human rights in the PA itself is ambiguous, recognising their relevance to climate change in principle while distancing the regime from their implementation in practice. Nevertheless, it is evident that, despite the evasive approach adopted, the very act of inclusion has affected the context of the climate change debate, serving to further fuel the active engagement of the UN human rights and gender machinery on climate change where it crosses into their respective remits. A similar situation arose in the cross-cutting of the gender/human rights/environment nexus (including climate change) expressed in the 2030 Agenda for Sustainable Development (Agenda 2030) (UN GA, 2015) and the Sustainable Development Goals (SDGs) (UNDP, 2015). This is significant as there is clearly acknowledged crossover between the UNFCCC and the SDGs and Agenda 2030, not least in respect of Goal 13, climate action, and its supporting targets (UN GA, 2015, para. 14). While gender is covered in the SDGs themselves, both discretely (under Goal 5) and as a cross-cutting concern in a number of other goals and appears in many of the regime's supporting targets 
(Morrow, 2018), it is more prominent still in Agenda 2030. Nevertheless, in both contexts, rights-based coverage is again effectively side-stepped (Morrow, 2018). However, flawed as the coverage offered may be, the fact that gender is included in the SDGs provides an additional route to invoke gender equality, which is significant in the context of the increasingly regularised interplay between the climate change and SDG regimes. The latter is indicated, for example, by the inclusion of 'Action on Climate and the SDGs' under UNFCCC topics (UN FCCC Topics, n.d.).

\section{A plethora of institutional activity - But to what avail?}

The UNFCCC regime machinery has, belatedly, engaged prolifically with the gender agenda and its approach has matured considerably, yet its impact has been at best limited. This begs the question, what is needed to do better? On paper, the building of a sound foundation of accurate and transparent data, its dissemination within the UNFCCC, and tying it in, however symbolically, with the human rights and SDG agendas more broadly, demonstrates some promise for more thoroughgoing engagement with gender and climate change than hitherto. Were this all that had been done, it would, however, have been open to interpretation as a cynical exercise in ecomodernism, favouring form over substance. However, latterly it has been joined by the promotion of institutional reflection, debate and change, which ostensibly provides a more grounded basis for addressing substantive gender inequality issues. In practice, though, progress, even within the UNFCCC's own constituent bodies, has been frankly unimpressive. Self-evidently, more needs to be done - but what? Bringing gender into sharper focus than ever before has made the pervasive nature of gender inequality even more apparent. This is important in itself, as it lays bare the root of the failure of UNFCCC initiatives to gain much traction - state inaction on gender equality. The failure of states to live up to their international legal commitments is notionally a source of political embarrassment vis-à-vis other states and stakeholders and often described as a potent lever to motivate states to action in both international human rights law (Cassel, 2001) and international environmental law (Benedick, 1998). Yet slow progress and even regression in gender equality suggest that both in general (as outlined above) and in the context of the UNFCCC shame does not always serve as an effective driver of state behaviour. The UNFCCC has done much to set its own house in order, but, as is readily apparent from the discussion above, if it is confined to hortatory approaches to its state signatories, these will not suffice to bring about deeper change, as states are effectively free to ignore exhortations to act on existing gender equality commitments. In theory, the UNFCCC could do more; in recognition of the pervasive and deeply entrenched nature of gender inequality, a suite of tools has been identified that can help to forge progress, for example, temporary quotas to promote participation (CEDAW, 2004; UN OHCHR, 2014). Failure to address gender equality could also be subject to innovative corrective action within the UNFCCC's competence, for example, targeting gender-unequal state delegations 
by limiting participation rights to a guaranteed minimum but rewarding genderequal delegations with support and increased opportunities to participate above that minimum. In practice, though, as an intergovernmental organisation, the UNFCCC is in a weak position to compel states to act, as it, in effect, relies on their goodwill to operate. The fundamental sovereign status of states in this area, as in all others, remains the ultimate brake on progress. Political buy-in and sustained commitment to the pursuit of gender equality by the UNFCCC's signatory states is crucial, but remains controversial for some states, standing in the way of consensus. Additionally, but relatedly, state financial buy-in is also necessary to further progress - if gender equality is not viewed as a priority, it is not adequately resourced and progress will be hampered. It is telling that most UNFCCC documents on gender equality repeat the refrain that action is subject to the availability of financial resources.

\section{What is needed? Updating, expanding and fully realising UNFCCC engagement with gender issues}

The UNFCCC began as a male-dominated, masculinist-oriented regime and despite concerted efforts to correct this, the continued paucity of women's participation and its limited impact underline that this remains largely the case in substance, if not in form. Insofar as equality between women and men within the global climate governance regime is concerned, we are dealing with a broadly improving picture, after a belated start, but the business in hand is very much unfinished and progress remains quite sporadic and slow overall. This is not the only area of gender concern where concerted action is needed. Our understanding of the complexity of sex and gender, extending far beyond the female/male binary, has been rediscovered (Independent Lens, 2015) and grown apace in recent years. The World Health Organisation (WHO) defines gender as referring to:

the roles, behaviours, activities, attributes and opportunities that any society considers appropriate for girls and boys, and women and men. Gender interacts with, but is different from, the binary categories of biological sex.

(WHO, n.d.)

Thus, an informed and current approach to gender must extend its reach beyond the conventional female/male binary and be genderqueered to embrace those of all sexes, genders and orientations and indeed those of none. The understanding of gender as expressed in our international institutions more generally (human rights bodies excepted, discussed briefly below) has now fallen far behind our social and scientific grasp of the issues that it raises and remains dominated by the female/male binary.

As Kenny has observed, feminist analysis has evolved beyond a simplistic sexed approach focused on 'women's issues' to embrace a broader perspective on gender as performance. Fully pursuing even this has, however, proven problematic when looking at issues of representation, 'where research continues to focus 
on female bodies as the "main vehicles" for institutional change and transformation' (Kenny, p. 94). It is also the case in global climate change governance that gender continues to be largely conflated with 'women's issues' and that broader gender concerns, notably those relating to LGBTQI+ persons, remain underinterrogated to the point of near invisibility. UN work in cognate areas, such as food security (UNEP, 2018, p. 33) suggests, in passing, that LGBTQI+ people face many of the same disadvantages as women, and as these issues intersect with climate change, it is therefore reasonable to assume that a broader notion of equality than that typically current should be applied to the treatment of genderbased vulnerability to climate change. This lacuna is fairly typical, as while the UN human rights machinery finally turned its attention to LGBTQI+ rights in the last few years, as was the case with women's issues for many years, other UN institutions remain relatively unengaged. It is also the case that the human rights activity in this area thus far remains fairly narrow, focusing primarily on firstgeneration (civil and political) rights (UN OHCHR, 2019). Second-generation (social and economic) and third-generation (solidarity) rights also need to be invoked, not least in the context of climate change, if we are to give full meaning to the universality of human rights and dignity in this regard; equal human rights are the entitlement of all, gender/no gender notwithstanding. Ebbs and flows in the respect accorded to human rights are, given the tide of human affairs, entirely to be expected. The core international protections owe their origins to reactions to the horrors of World War Two - and it speaks volumes that it was deemed necessary to articulate and garner state support for them in the context of vast infringements of the most basic entitlements of human beings. While arguments on the efficacy of international human rights law are commonplace (Cassel, 2001), what it does provide is an articulation of core protections that serves as a yardstick to evaluate state (and international institutional) behaviour. As the boundaries that human rights protection delineate are tested, not least by climate change, the willingness - or not - of the international community to deploy rights rhetoric as prevention and/or cure is immensely revealing. Human rights commitments, then, have an important role to play in the conduct of human affairs, albeit as part of a broad, complex and multi-layered framework of legal, political and social processes (Cassel, 2001). Where gender and human rights are concerned, a global backlash fuelled by some religious and ultra-conservative groupings is currently observable in relation to both women's (UN OHCHR, 2014; Lilja and Johansson, 2018) and LGBTQI+ rights (UN OHCHR, 2019). This backlash demonstrates the precarity of even the limited progress that we have made in this regard and that there is a real danger of regression that will have broad ramifications across our societies and act to the detriment of all.

\section{Conclusion - Process is all very well, but progress must be prioritised}

While there has been some progress in addressing gender in the global climate regime, an economics-driven, technocratic stance toward climate change 


\section{Karen Morrow}

continues to dominate. Insofar as gender, narrowly defined across the female/ male binary, is concerned, advancement has been uneven and achingly slow. As Caroline Criado Perez puts it:

we have to close the female representation gap. When women are involved in decision-making, in research, in knowledge production, women do not get forgotten. Female lives and perspectives are brought out of the shadows.

(Perez, 2019, p. 318)

It is now also readily apparent that a largely binary focus is too narrow to fully address gender issues (UNEP, 2018, p. 196). Furthermore, broader gender identity and sexuality-related diverse perspectives share many of the hallmarks of exclusion that have long been identified with regard to the basic gender binary. Gender equality is not a novel claim, nor should it be regarded as a radical one, though given the paucity of progress that we have made in its realisation, one could be excused for thinking that it was both. It stands to our shame that the constant refrain that commentators must adopt in this field is slow progress; more needs to be done. It remains the case that, in an international legal system founded on state sovereignty (Dixon, 2013) and hallmarked by the limited enforcement capacity of a regime based on consent and consensus (Dixon, 2013), bodies such as the UNFCCC, however committed they are to advancing gender equality, are politically constrained in getting states to live up to their commitments. While more compelling approaches are notionally available, political realism in the context of the UNFCCC suggests that persuading states to act will continue to be the standard approach. Limited progress to date, however, suggests that this is incapable of delivering the paradigm shift required. It remains the case that representation - both in presence (which is necessary but not sufficient) and, in turn, in influence - is the sine qua non of progress on gender equality. Selfinterest supports this; if climate change has taught us nothing else, it is that it will require the whole range of human ingenuity and agency to tackle it. It requires an inclusive approach that brings all human perspectives, female, LGBTQI+ and male, to the table - to proceed otherwise is a further act of self-sabotage, adding an avoidable additional challenge to the already obdurate problems that we face.

\section{Notes}

1 Initially there were 11 constituted bodies in total: the Executive Board of the clean development mechanism (CDM Executive Board); the Joint Implementation Supervisory Committee (JISC); the Compliance Committee facilitative branch; the Compliance Committee enforcement branch; the Least Developed Countries Expert Group (LEG); the Consultative Group of Experts on National Communications from Parties not included in Annex I to the Convention (CEG); the Adaptation Fund Board (AFB); the Technology Executive Committee (TEC); the Adaptation Committee (AC); the Standing Committee on Finance (SCF); and the Advisory Board of the Climate Technology Centre and Network (CTCN Advisory Board). The Executive Committee of the Warsaw International Mechanism for Loss and Damage associated with Climate Change Impacts (Executive Committee of the WIM) was added from 
2014 and included in analysis of the report statistics from 2015. The Paris Committee on Capacity Building (PCCB) was added from 2017. The Facilitative Working Group of the Local Communities and Indigenous Peoples Platform (figures analysed relate to government members only) and the Katowice Committee of Experts on the Impacts of the Implementation of Response Measures were added in 2019.

2 Namely the AC, AFB, CDM Executive Board, CGE, CTCN Advisory Board, JISC, LEG, PCCB, SCF, TEC and Executive Committee of the WIM. Exceptions were taskor time-based.

\section{References}

Benedick, R. E. (1998) Ozone Diplomacy: New Directions in Safeguarding the Planet. Enlarged Edition. Cambridge, MA: Harvard University Press.

Cassel, D. (2001) 'Does International Human Rights Law Make a Difference?', Chi. J. Int'l L., 2, pp. 121-135.

CBD, UNCCD, UNFCCC (2012) The Rio Conventions: Action on Gender [online]. Available at: https://unfccc.int/resource/docs/publications/roi_20_gender_brochure.p df (Accessed: 23 July 2020).

CEDAW (2004) General Recommendation No. 25, on Article 4, Paragraph 1, of the Convention on the Elimination of All Forms of Discrimination against Women, on Temporary Special Measures [online]. Available at: https://www.refworld.org/docid /453882a7e0.html (Accessed: 05 August 2018).

CEDAW (2018) General Recommendation No. 37 on Gender-Related Dimensions of Disaster Risk Reduction in the Context of Climate Change, CEDAW/C/GC/37 [online]. Available at: https://tbinternet.ohchr.org/Treaties/CEDAW/Shared\%20Do cuments/1_Global/CEDAW_C_GC_37_8642_E.pdf (Accessed: 31 July 2020).

Charlesworth, H. (2002) 'The Hidden Gender of International Law', Temp. Int'l E' Comp. L.J., 16, pp. 93-102.

Criado Perez, C. (2019) Invisible Women: Exposing Data Bias in a World Designed for Men. London: Chatto and Windus.

Dixon, M. (2013) Textbook on International Law. 7th Edition. Oxford: Oxford University Press.

Independent Lens (2015) A Map of Gender-Diverse Cultures [online]. Available at: https ://www.pbs.org/independentlens/content/two-spirits_map-html/ (Accessed: 07 August 2020).

Kenny, M. (2007) 'Gender, Institutions and Power: A Critical Review', Politics, 27(2), pp. 91-100.

Lilja, M. and Johansson, E. (2018) 'Feminism as Power and Resistance: An Inquiry into Different Forms of Swedish Feminist Resistance and Anti-Genderist Reactions', Soc. Incl., 6(4), pp. 82-94.

Morrow, K. (2006) 'Not so Much a Meeting of Minds as a Coincidence of Means: Ecofeminism, Gender Mainstreaming and the UN', Thomas Jefferson Law Journal, 28(2), pp. 185-204.

Morrow, K. (2017a) 'Integrating Gender Issues into the Global Climate Change Regime', in Buckingham, S. and Le Masson, V. (eds.) Understanding Climate Change through Gender Relations. London: Routledge, pp. 31-44.

Morrow, K. (2017b) 'Changing the Climate of Participation: The Gender Constituency in the Global Climate Change Regime', in Macgregor, S. (ed.) Routledge Handbook on Gender and Environment. London: Routledge, pp. 398-411. 


\section{Karen Morrow}

Morrow, K. (2018) 'Gender and the Sustainable Development Goals', in French, D., Louis, J., and Kotzé, L. J. (eds.) Sustainable Development Goals Law, Theory and Implementation. Cheltenham: Edward Elgar, pp. 149-172.

Meyer, M. K. and Prugl, E. (eds.) (1999) Gender Politics in Global Governance. Lanham: Rowland \& Littlefield.

Rochette, A. (2017) 'The Integration of Gender in Climate Change Mitigation and Adaptation in Quebec', in Griffin Cohen, M. (ed.) Climate Change and Gender in Rich Countries: Work, Public Policy and Action. London: Earthscan from Routledge, pp. 250-265.

UN BDPA (1995) Beijing Declaration and Platform for Action [online]. Available at: https://www.unwomen.org/-/media/headquarters/attachments/sections/csw/pfa_e_fina 1_web.pdf?la=en\&vs=800 (Accessed: 29 July 2020).

UN CEDAW (1979) Convention on the Elimination of All Forms of Discrimination against Women UNGA Res 34/180 of 18 December 1979 [online]. Available at: https ://www.un.org/womenwatch/daw/cedaw/text/econvention.htm (Accessed: 29 July 2020).

UNDP (2015) Sustainable Development Goals [online]. Available at: http://www .undp.org/content/undp/en/home/sustainable-development-goals.html (Accessed: 04 August 2020).

UNEP (2018) Global Gender and Environment Outlook [online]. Available at: https://we docs.unep.org/bitstream/handle/20.500.11822/14764/Gender_and_environment_ou tlook_HIGH_res.pdf?sequence=1\&isAllowed=y (Accessed: 22 July 2020).

UN FCCC (1992) United Nationals Framework Convention on Climate Change [online]. Available at: https://unfccc.int/resource/docs/convkp/conveng.pdf (Accessed: 23 July 2020).

UN FCCC (2001) FCCC/CP/2001/13/Add.4 Decision 36/CP.7 Improving the Participation of Women in the Representation of Parties in Bodies Established under the United Nations Framework Convention on Climate Change or the Kyoto Protocol [online]. Available at: https://unfccc.int/resource/docs/cop7/13a04.pdf (Accessed: 23 July 2020).

UN FCCC (2012) Decision 23/CP.18 on 'Promoting Gender Balance and Improving the Participation of Women in UNFCCC Negotiations and in the Representation of Parties in Bodies Established Pursuant to the Convention or the Kyoto Protocol' FCCC/ CP/2012/8/Add.3 [online]. Available at: http://unfccc.nt/files/bodies/election_and_me mbership/application/pdf/cop18_gender_balance.pdf (Accessed: 23 July 2020).

UN FCCC (2013) Workshop on Gender, Climate Change and the UNFCCC Workshop on Gender, Climate Change and the UNFCCC [online]. Available at: http://unfccc .int/files/adaptation/application/pdf/in_session_workshop_agenda_web.pdf (Accessed: 23 July 2020).

UN FCCC (2014) Decision 18/CP.20 The Lima Work Programme on Gender Online FCCC/CP/2014/10/Add 3 [online]. Available at: https:/unfccc.int/sites/default/files/r esource/docs/2014/cop20/eng/10a03.pdf (Accessed: 04 August 2014).

UN FCCC (2015a) Draft Paris Agreement FCCC/ADP/2015/L.6 [online]. Available at: https://unfccc.int/files/bodies/awg/application/pdf/draft_paris_agreement_5dec15.pdf (Accessed: 28 July 2020).

UN FCCC (2015b) The Paris Agreement FCCC/CP/2015/10/Add.1 [online]. Available at: https://unfccc.int/resource/docs/2015/cop21/eng/10a01.pdf (Accessed:28 July 2020)

UN FCCC (2016) Decision 21/CP. 22 Gender and Climate Change [online]. Available at: https://unfccc.int/sites/default/files/resource/docs/2016/cop22/eng/10a02.pdf (Accessed: 04 August 2017). 
UN FCCC (2017) Decision 3/CP.23 Establishment of a Gender Action Programme FCCC/CP/2017/11/Add.1 [online]. Available at: https:/unfccc.int/resource/docs/20 17/cop23/eng/11a01.pdf\#page=13 (Accessed: 04 August 2020).

UN FCCC TP (2018) Entry Points for Integrating Gender Considerations into UNFCCC Workstreams FCCC/TP/2018/1 [online]. Available at: https://unfccc.int/sites/default/ files/resource/01.pdf (Accessed: 31July 2020).

UN FCCC (2019a) Progress in Integrating a Gender Perspective in Constituted Body Processes (Synthesis Report) FCCC/CP/2019/8 [online]. Available at: https://unfccc. int/sites/default/files/resource/cp2019_08E.pdf (Accessed: 03 August 2019).

UN FCCC (2019b) Implementation of the Lima Work Programme on Gender and Its Gender Action Plan FCCC/SBI/2019/15/Add.1 [online]. Available at: https://unfccc. int/sites/default/files/resource/sbi2019_15E.pdf (Accessed: 04 August 2020).

UN FCCC (2019c) Decision 3/CP.25 Enhanced Lima Work Programme on Gender and Its Gender Action Plan FCCC/CP/2019/3/Add.1 ADVANCE VERSION [online]. Available at: https://unfccc.int/sites/default/files/resource/cp2019_13a01_adv.pdf (Accessed: 05 August 2020).

UN FCCC (2020) Integrating Gender into National Climate Actions-Online Regional Workshops [online]. Available at: https:/unfccc.int/news/integrating-gender-into-na tional-climate-actions-online-regional-workshops (Accessed: 31 July 2020).

UN FCCC (undated) UNFCCC Topics [online]. Available at https://unfccc.int/topics (Accessed: 28 July 2020).

UN FCCC (undated) Gender and Climate Change Documents [online]. Available at: https://unfccc.int/topics/gender/resources/documentation-on-gender-and-climate-c hange (Accessed: 12 October 2020).

UN GA (2015) A/Res/70/1 Transforming Our World: The 2030 Agenda for Sustainable Development, 21 October 2015 [online]. Available at: http:/www.un.org/ga/search/view :doc.asp?symbol=A/RES/70/1\&referer=/english/\&Lang=E (Accessed: 04 August 2020).

UN OHCHR (2019) Born Free and Equal. 2nd Edition [online]. Available at: https:// www.ohchr.org/Documents/Publications/Born_Free_and_Equal_WEB.pdf (Accessed: 22 July 2020).

UN OHCHR (2014) Women's Rights are Human Rights [online]. Available at: https ://www.ohchr.org/Documents/Events/WHRD/WomenRightsAreHR.pdf (Accessed: 22 July 2020).

UN OHCHR (2019) Human Rights Obligations Relating to the Enjoyment of a Safe, Clean, Healthy and Sustainable Environment A/74/161 [online]. Available at: https:// undocs.org/A/74/161 (Accessed: 31 July 2020).

UN OHCHR (undated) International Human Rights Law [online]. Available at: https ://www.ohchr.org/en/professionalinterest/Pages/InternationalLaw.aspx (Accessed: 31 July 2020).

UN SPFII Et al (2010) Gender and Indigenous Peoples [online]. Available at: https://ww w.un.org/esa/socdev/unpfii/documents/Briefing\%20Notes\%20Gender\%20and\%20Indi genous\%20Women.pdf (Accessed: 05 August 2020).

UN Women (2012) 8th Conference of the Parties to the United Nations Framework Convention on Climate Change [online]. Available at: https://www.unwomen.org/e n/news/stories/2012/12/cop18-landmark-decision-adopted (Accessed: 23 July 2020).

Wängnerud, L. (2009) 'Women in Parliaments: Descriptive and Substantive Representation', Annu. Rev. Polit. Sci., 12, pp. 51-69.

WHO (undated) Gender [online]. Available at: https://www.who.int/health-topics/ gender (Accessed: 22 July 2020). 